\title{
Emotional Intelligence and its Impact on Employee Job Satisfaction of IT Companies in Hyderabad: A Case Study
}

\author{
Mallela Subrahmanya Kameswara Rao ${ }^{1}$, Dr. Vidyadhar Reddy Aileni ${ }^{2}$ \\ ${ }^{1}$ Research Scholar, ${ }^{2}$ Professor \& Director \\ ${ }^{1}$ Department of Management, Rayalaseema University, Andhra Pradesh \\ ${ }^{2}$ Department of Management Studies, NALSAR University of Law, Hyderabad, Telangana, India
}

\begin{abstract}
In the modern working environment, the emotional intelligence and job satisfaction are the two concepts which are becoming highly interesting for many persons in any organization. These two aspects serve as a competitive edge in the personal and organizational life. However, there are only a few research studies that have explored the most important factors which have drastically affected these two concepts.
\end{abstract}

The main objective of this study is to examine the relationship between the emotional intelligence and job satisfaction factors. Researcher also tried to analyze and assess the reasons about how the designation, experience and marital status of an employee would affect his or her emotional intelligence and job satisfaction while doing a job in an organization.

In the present research study, the data was collected based on a survey from 500 respondents of selected IT firms operating in Hyderabad, India using self administered questionnaires. The findings were made after the Data analysis with the help of standard statistical tools such as Karl Pearson coefficient of correlation, Analysis of variance (ANOVA), Student's t- test and other statistics and inferences.

Based on the statistical analysis of data, the present study revealed that there was a very high and significant positive relationship between the two factors of emotional intelligence and job satisfaction. The study also showed that the designation of the employee does not affect his job satisfaction and emotional intelligence factors. However, the experience of an employee and his / her marital status carry significant effects on the two factors of emotional intelligence and job satisfaction.

KEY WORDS: Emotional Intelligence, Job satisfaction, Performance, Self-Awareness, Adaptability, Social Awareness, Relationship Management

\section{INTRODUCTION}

We are living in the period of globalization where there is high cultural, scientific, economic and social exchange in almost all countries. The success of any person would greatly depend on many personal factors viz., personal attitude\& behavior, Self discipline, parental support, good education, social network, financial Etc. Irrespective these factors, there can be a failure for any person at any point of time.

The Low emotional intelligence (EI) is one of the important root causes for this failure or poor performance. The emotional intelligence is nothing but the ability to manage the emotions of self and others intelligently for good purpose. The EI would comprise of many acquired skills and competencies that would predict and provide positive outcomes at home with one's family, in school, and at work. Those emotionally intelligent people would naturally be healthier, less depressed, more productive at work, and have better relationships. There has been a significantly greater demand for higher level of interrelationships, mutual understanding and greater productivity of any employee at the place of work. A thorough and good knowledge about the emotions of self and others, and an ability to manage them would 
help a person to gain the success and satisfaction in his work in an organization.

Though the intelligence quotient (IQ) is an important factor which would determine the success of a person, many research studies have shown that beyond a certain point, it is always the emotional quotient that would matter more than an IQ under working environment.The job satisfaction of an employee is always an integral component of any organizational climate or environment. It is also an important element in the management of the relationship of the employee with others. It is the positive emotional state that would occur when the job of a person seems to fulfill all the important job values provided. These job values are highly compatible with the needs of a person.

The investigator has a feeling that it would be very much interesting to study if there is any significant correlation between the job satisfaction and the emotional intelligence of the employee in an organization. This research study would also propose to study about the job satisfaction and emotional intelligence based on the designation of the employee. An attempt is also made to study about the job satisfaction and emotional intelligence based on the work experience and his or her marital status.

\section{Literature review}

Emotional intelligence: In an organization, different people will have different levels of emotion which will affect the individual work and over-all productivity over a period of time. The emotional intelligence (EI) of an employee would describe about the ability, capacity, skill or in the case of the trait of an EI model, a self-perceived grand ability to identify, assess, manage and control the emotions of one self, others, and also of groups of persons.

The emotional intelligence factor in a person is very important and is considered to play a significant and crucial role in the modern work life. The principles of emotional intelligence would always help in critically evaluating the employee behavior, management styles, attitudes, inter-personal skills and potentials. It is considered to have a great relevance in the areas like job profiling, planning, recruitment and selection. Another major advantage of the emotional intelligence is that it would allow employees to better understand and mange not only their emotions but also the emotions of others . Many psychological studies have shown that a clear understanding and suitable control of emotions would play a highly significant role in gratifying one's life and also the work environment.

Job satisfaction: Among different outcomes, the job satisfaction is very important not only from the employee point of view, but also from the organization point of view. The job satisfaction of an employee is a topic which has got wide appreciation in the academics as well as in different industrial organizations. It refers to an employee's involvement and affective reaction to the work that he or she is doing in the job in terms of how much it would satisfy and the desired outcomes. The job satisfaction actually refers to the extent to which the employee likes his/her job or it may be considered as the emotional attachment one has with his/her job. With a better satisfaction, the organization will have a better turnover of work and ultimate over-all productivity and profits in a year.

Emotional intelligence and job satisfaction: Daniel Goleman has identified a set of competencies that would differentiate the individuals having different levels of emotional intelligence. The different competencies can be grouped into four clusters as follows:

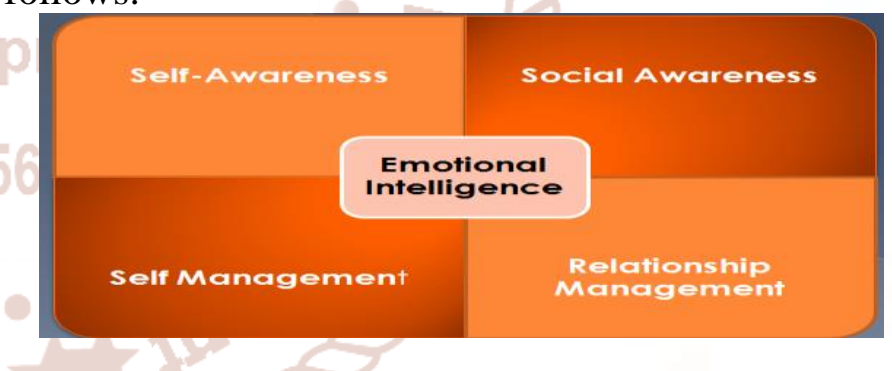

Cluster 1: The Self-Awareness or the capacity of an individual employee for understanding his or her own emotions, apart from strengths and weakness. Some of the major components of this cluster would consist of the Emotional Awareness, Self-Assessment and self-Confidence.

Cluster 2: The Self-Management or the Capacity for effectively and efficiently managing his/ her own motive and behavior. This cluster would consist of different aspects of Self-Control, Achievement, Orientation Initiative, Conscientiousness, Trustworthiness and Adaptability.

Cluster 3: The Social Awareness or the ability to understand the feelings, views and 
motive behind the actions of other employees in an organization. This cluster would include the different aspects like the Empathy, Organizational Awareness and service Orientation.

Cluster 4: Relationship Management / The Social Skills or the ability of a person to achieve the desired results from other employees and attain his or her own personal goal. This cluster would include the different aspects like Leadership, Influence, Communication, Conflict Management, Team works, Building Bonds and Collaboration.

It can be easily observed that the competencies mentioned in the first three clusters as detailed above are considered to be the essential requirement for an individual to become successful in the fourth cluster.

In the present day conditions, the job satisfaction derived by an employee by working in an organization is an important area of the complex research and theory. Herzberg proposed that the job satisfaction would be composed of 2 elements, viz., "hygiene factors" and "motivation" factors. The hygiene factors are nothing but the necessary condition, but not the sufficient condition for maximum or high job satisfaction for an employee in any organization. The hygiene factors are significantly correlated to the administrative factors such as the work environment, pay and other benefits or facilities associated with the job of an employee.

It is observed that the different motivation factors are significantly correlated with the factors like degree of autonomy and decision making capacity associated with the job of a person in an organization. It would also include the factors that would make the jobs more intrinsically rewarding which include the interesting content, conducive team environment, importance of the work, relationships, good leadership and various other factors which change from time to time.

In the business, the Emotional Quotient programs should be used to build the organizational capacity with the objective of bringing out the best in the people (or employees) and thus forming powerful workplace with suitable relationships. This would help for increasing the engagement, trust and integrity of the employees for building more effective teams, retain great employees, provide an exceptional customer care, and effectively managing the change over a period of time.

The development of skills like the communication skills, logical skills, comprehension skills, creative skills, and management skills must always get top priority compared to others in any organization. The emotional intelligence test should be used in the workplace for giving the promotions, staff reviews, recruitment in any organization.

With regard to the concept of emotional intelligence, an effective action would always require more efforts and energy for implementation compared to merely the rational thought. It is easy to say, but it is very difficult to implement among a group of people. The emotion of any person would be highly critical for either providing energy or energizing and directing the behavior in a cool manner. If any person (employee) has to be happy and successful in life, he or she must have more than just the cognitive ability as measured by the Intelligence Quotient tests. The research work documented by many research workers in different countries has consistently indicated that the Intelligence Quotient scores and the academic intelligence scores do not significantly predict the important life outcomes very well. Further, the job satisfaction of an employee in an organization is always an integral component of the organizational climate and is an important element in the management of relationship among employees and establishing a cordial and working environment. Any organization should always aim to take firm and concrete steps for the purpose of improving the job satisfaction of different employees.

Any employee would continuously for a longer period in any organization, only if he derives maximum job satisfaction. Otherwise, he or she will keep on changing the organizations in search of a suitable job. Thus among different indicators, the job satisfaction is the most important indicator of how different employees would feel about the activities in their jobs. It is also a predictor of the work behaviors of employees such as the organizational citizenship, absenteeism, and turnover of work. Further, the job satisfaction of an employee will partially mediate the relationship among different personality variables and deviant work behaviors in any organization. 
By and large, the emotional intelligence of employees will have a positive association with their job satisfaction. In any organization, the employees with higher emotional intelligence will tend have higher job satisfaction and those with lower emotional intelligence will have a lower job satisfaction. The employees with higher emotional intelligence would always develop better strategies for overcoming the possible stress related consequences. Compared to this, the employees with less emotional intelligence will not be able to develop superior strategies for overcoming the situations caused by the stress in either work or personal matters. Apart from this, the employees with higher emotional intelligence are an asset to the organization, in the sense that they will be able to influence the emotions of other employees.. The result would be that they will be able to boost their own morale as well as the morale of the coworkers.

\section{Methodology}

In our present research study, we used a descriptive method where the "data were collected to test the different null hypotheses and also to answer the questions concerning about the current status of the research problem". A suitable field survey method was selected and adopted for collection of the data and analysis in the present study.

The research study was conducted by contacting and collecting the data from the employees working in an IT firms operating in Hyderabad, India. The data of different parameters were collected from about 500respondents of the firm working in different locations self administered appropriate questionnaires. The data were tabulated and analyzed using different statistical procedures. Finally statistical inferences have been drawn and suitable findings were made based on the research study.

Research Objectives: The following are the core objectives of the research :

1. Relationship between the emotional intelligence andjob satisfaction of the employees.

2. The effect of Emotional Intelligence on the Job Satisfaction

3. How the designation, experience and marital status of an employee would affect his or her emotional intelligence and job satisfaction.

Research Methodology: The research study was conducted with a considerable sample size of data were used to analyze and assess the relationships and effect of different factors of emotional intelligence and their influence on the employees job satisfaction.

Research Design: Descriptive research design to determine how the Emotional Intelligence factors have contributed to improve the employee job satisfaction and the competitive advantage through technology. The study relied mostly on the primary data that was collected using the interview mode with many open-ended questions. Interviewing the sample respondents was considered a suitable method for conducting the qualitative research.

Sample: The study was conducted with a selected sample of 500 respondents from 20 IT companies in Hyderabad.

Statistical tools: Correlation, Regression, Standard deviation, t-test, Cranach's Alpha (for assessing the reliability of data).

Development of Hypotheses: Based on the different objectives of our research study, the following hypotheses have been formulated for further testing based on appropriate statistical tests.

H1: There is no significant relationship between the job satisfaction and emotional intelligence of the employees considered for this study.

H2: There is no significant difference in the mean scores of job satisfaction based on the designation of the employees.

$>$ H3: There is no significant difference in the mean scores of the emotional intelligence based on the designation of the employees.

$\mathrm{H} 4$ : There is no significant difference in the mean scores of the job satisfaction based on the experience of the employees.

H5: There is no significant difference in the mean scores of the emotional intelligence based on the experience of the employees.

$>$ H6: There is no significant difference in the mean scores of the job satisfaction based on the marital status of the employees.

$>$ H7: There is no significant difference in the mean scores of the emotional intelligence based on the marital status of the employees.

Emotional quotient tool: For carrying out the Emotional Quotient Test, the researcher used appropriate working with the emotional intelligence, Bantam Books, New York as the main source for testing and analysis. 
Data Analysis

Table: 1 Emotional Intelligence and Job satisfaction factors

\begin{tabular}{|c|l|c|}
\hline S. No & \multicolumn{1}{|c|}{ Factors } & Significance at 100 \% Level \\
\hline 1 & Adaptability & 74 \\
\hline 2 & Assertiveness & 68 \\
\hline 3 & Emotional appraisal & 79 \\
\hline 4 & Emotion control & 87 \\
\hline 5 & Emotion expression & 95 \\
\hline 6 & Emotion management & 86 \\
\hline 7 & Low impulsiveness & 77 \\
\hline 8 & Relationships & 69 \\
\hline 9 & Self-esteem & 82 \\
\hline 10 & Self-motivation & 83 \\
\hline 11 & Social awareness & 86 \\
\hline 12 & Stress management & 75 \\
\hline 13 & Well-being & 74 \\
\hline 14 & Self-control & 84 \\
\hline 15 & Emotionality & 81 \\
\hline 16 & Sociability & 87 \\
\hline
\end{tabular}

Emotional Intelligence and its impact on Employees impulsiveness 77\%, Relationships 69\%, Self-esteem Job satisfaction in IT companies: A case study factors are presented in table1. All the above factors such as $82 \%$, Self-motivation $83 \%$, Self-motivation $83 \%$, Social awareness $86 \%$, stress management 74 , wellAdoptability 74\%, Assertiveness 68\%, Emotional being 74\%, Self-control 84\%, Emotionality 81\%, appraisal 79\%, Emotion Control 87\%, Emotion Sociability 87\% highly accepted by the majority of expression $95 \%$, Emotion management $86 \%$, Low the respondents.

Table 2: Demographic factors

\begin{tabular}{|c|c|c|c|}
\hline & Description & Sample Respondents & Percentage \\
\hline Age & $21-23$ & HITEII 120 & 24 \\
\hline 20 & $24-26$ & 104 & 21 \\
\hline+8 & $27-29245$ & $8=647098$ & 20 \\
\hline & $30-32$ & 79 & 16 \\
\hline & $33-35$ & 99 & 19 \\
\hline & Subtotal & 500 & 100 \\
\hline Gender & $\sqrt{x-5}$ & 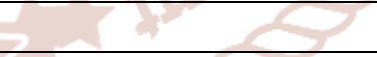 & \\
\hline & Male & 254 & 51 \\
\hline & Female & 246 & 49 \\
\hline & Subtotal & 500 & 100 \\
\hline \multicolumn{4}{|l|}{ Educational Level } \\
\hline & 12th STD & & 12 \\
\hline & Diploma & & 8 \\
\hline & Degree & & 26 \\
\hline & Postgraduate & & 54 \\
\hline & Subtotal & & \\
\hline \multicolumn{4}{|l|}{ Respondents } \\
\hline & Managerial cadre & & 20 \\
\hline & Middle level & & 24 \\
\hline & Operative level & & 36 \\
\hline & consultants level & & 20 \\
\hline & Subtotal & & 100 \\
\hline
\end{tabular}

The age, gender educational level and the respondent's details had presented in Table.2. 
International Journal of Trend in Scientific Research and Development (IJTSRD) ISSN: 2456-6470

Table3: EI and Job performance standards: Factor Analytics

\begin{tabular}{|c|l|l|c|}
\hline Rating & \multicolumn{1}{|c|}{ Standard } & \multicolumn{1}{|c|}{ Description } & Factor loadings \\
\hline 1 & Goals & $\begin{array}{l}\text { Job holders goals and performance acceptable } \\
\text { level }\end{array}$ & 0.824 \\
\hline 2 & Responsibilities & $\begin{array}{l}\text { Job holders have achieved most of their goals by } \\
\text { performing key responsibilities }\end{array}$ & 0.925 \\
\hline 3 & Good & $\begin{array}{l}\text { achieved all of their goals and performance is at a } \\
\text { fully acceptable level }\end{array}$ & 0.798 \\
\hline 4 & Superior & $\begin{array}{l}\text { achieved all their goals and have significantly } \\
\text { exceeded a fully acceptable level }\end{array}$ & 0.852 \\
\hline 5 & Outstanding & $\begin{array}{l}\text { significantly exceeded all their goals and have } \\
\text { performed exceptionally well throughout the year }\end{array}$ & 0.924 \\
\hline
\end{tabular}

Emotional intelligence and job performance standard factors presented in Table3. The factor loadings of Job holders goals and performance acceptable level $0.824 \%$, Job holders have achieved most of their goals by performing key responsibilities $0.925 \%$, achieved all of their goals and performance is at a fully acceptable level $0.798 \%$, achieved all their goals and have significantly exceeded a fully acceptable level $0.852 \%$, significantly exceeded all their goals and have performed exceptionally well throughout the year $0.924 \%$. All these factors had highly influencing the improving the employees job performance in terms of goal achievement superiors subordinate relations and performance related factors.

Table4: Descriptive statistics of Emotional Intelligence and Job performance factors

\begin{tabular}{|l|c|c|}
\hline \multicolumn{1}{|c|}{ Variable } & Mean & SD \\
\hline Age & 3.77 & 0.987 \\
\hline Experience & 8.57 & 0.876 \\
\hline \multicolumn{1}{|c|}{ Performance traits } & 4.56 & 0.765 \\
\hline Sociability & 4.97 & 0.745 \\
\hline Emotionality & 5.64 & 0.762 \\
\hline Self-Control & 4.87 & 0.749 \\
\hline Well Being & 5.67 & 0.874 \\
\hline Average Performance Rating & 3.87 & 0.877 \\
\hline \multicolumn{1}{|c|}{ Career Advancement } & 3.17 & 0.866 \\
\hline Rank & 2.64 & 0.787 \\
\hline No. of Promotions & 2.89 & 0.912 \\
\hline Annual Salary & 4.42 & 0.765 \\
\hline \multicolumn{1}{|c|}{ Educational Attainment } & 4.12 & 0.865 \\
\hline Leaving Cert Points & 2.65 & 0.744 \\
\hline Level of Education & 3.78 & 0.922 \\
\hline
\end{tabular}

Descriptive statistics of Emotional Intelligence and Job performance factors shown in Table4. the relationship between emotional intelligence with age, mean values 3.77 , experience 8.57 , performance traits 4.56, Sociability 4.97, emotionality 5.64 , self-control
4.87, well being 5.67, average performance rating 3.87, career advancement 3.17, rank 2.64, No.of promotions $2.89 \mathrm{k}$, Annual salary 4.42 , educational attainment 4.12 , leaving cert points 2.65 , level of education 3.78. All these mean values and standard deviation values had positively correlated by establishing a positive kind of inter relationship between emotional intelligence and the above stated factors.

Table5: Reliability Analysis of Emotional Intelligence and Job performance factors

\begin{tabular}{|c|c|c|}
\hline Factors & $\begin{array}{c}\text { Cronbach's } \\
\text { Alpha }\end{array}$ & $\begin{array}{c}\text { N of } \\
\text { Items }\end{array}$ \\
\hline Work culture & 0.988 & 5 \\
\hline Performance at Work & 0.977 & 5 \\
\hline Career Advancement & 0.866 & 5 \\
\hline Educational Attainment & 0.877 & 5 \\
\hline
\end{tabular}

Reliability Analysis of Emotional Intelligence and Job performance factors disclosed in Table 5 representing Cronbach's Alpha values in respect of work culture 0.988, Performance at work 0.977, Career Advancement 0.866, Educational Attainment 0.877. The reliability test had given a positive kind of relationship and positive results in respect of emotional intelligence and the above key factors.

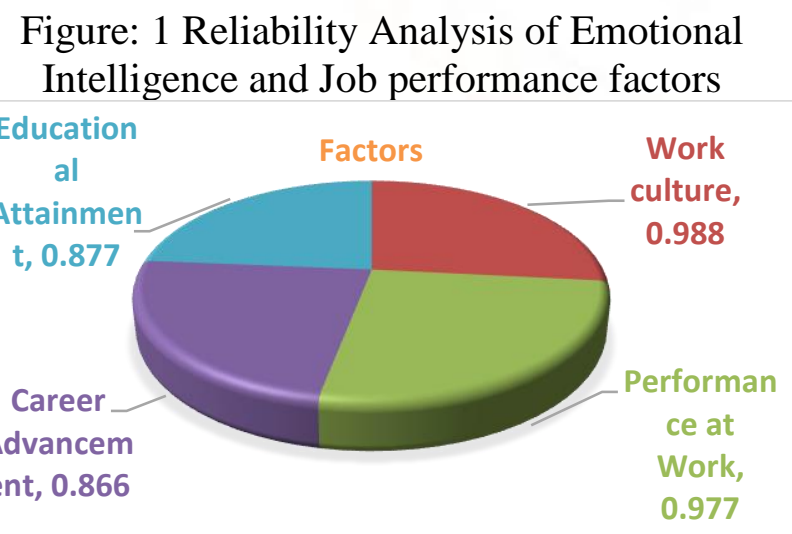


International Journal of Trend in Scientific Research and Development (IJTSRD) ISSN: 2456-6470

Table6: Pearson Correlation Coefficients between Variables

\begin{tabular}{|c|c|c|c|c|c|c|c|}
\hline Standards & $\begin{array}{c}\text { Career } \\
\text { Advancement }\end{array}$ & $\begin{array}{c}\text { Educatio } \\
\text { nal }\end{array}$ & $\begin{array}{c}\text { Performa } \\
\text { nce }\end{array}$ & Age & Gender & $\begin{array}{c}\text { Experien } \\
\text { ce }\end{array}$ & $\begin{array}{l}\text { Rating } \\
\text { Average }\end{array}$ \\
\hline $\begin{array}{l}\text { Career } \\
\text { Advancement }\end{array}$ & $1 \mathrm{Sig} 0.000$ & & & & & & \\
\hline Educational & $\begin{array}{l}0.333 \mathrm{Sig} \\
0.004 * *\end{array}$ & $\begin{array}{l}1 \mathrm{Sig} \\
0.000 \\
\end{array}$ & & & & & \\
\hline Performance & $\begin{array}{l}0.284 \mathrm{Sig} \\
0.017^{* *}\end{array}$ & $\begin{array}{l}0.031 \text { Sig } \\
0.362\end{array}$ & $\begin{array}{l}1.000 \mathrm{Sig} \\
0.000\end{array}$ & & & & \\
\hline Age & $\begin{array}{l}0.504 \mathrm{Sig} \\
0.000^{* * *}\end{array}$ & $\begin{array}{l}-0.107 \\
\text { Sig } 0.112 \\
\end{array}$ & $\begin{array}{l}0.009 \text { Sig } \\
0.460\end{array}$ & $\begin{array}{l}1.000 \mathrm{Sig} \\
0.000\end{array}$ & & & \\
\hline Gender & $\begin{array}{l}-0.014 \text { Sig } \\
0.436\end{array}$ & $\begin{array}{l}-0.114 \\
\text { Sig } 0.097\end{array}$ & $\begin{array}{l}-0.031 \\
\text { Sig } 0.361\end{array}$ & $\begin{array}{l}0.015 \text { Sig } \\
0.434\end{array}$ & $\begin{array}{l}1.000 \mathrm{Sig} \\
0.000\end{array}$ & & \\
\hline Experience & $\begin{array}{l}0.550 \mathrm{Sig} \\
0.000^{* * *}\end{array}$ & $\begin{array}{l}-0.263 \\
\text { Sig0.001 } \\
* * *\end{array}$ & $\begin{array}{l}0.065 \text { Sig } \\
0.229\end{array}$ & $\begin{array}{l}0.770 \\
\text { Sig0.000 } \\
* * *\end{array}$ & $\begin{array}{l}0.016 \text { Sig } \\
0.430\end{array}$ & $\begin{array}{l}1.000 \mathrm{Sig} \\
0.000\end{array}$ & \\
\hline $\begin{array}{l}\text { Rating } \\
\text { Average }\end{array}$ & $\begin{array}{l}0.582 \mathrm{Sig} \\
0.000^{* * *}\end{array}$ & $\begin{array}{l}0.216 \mathrm{Sig} \\
0.007 * *\end{array}$ & $\begin{array}{l}0.255 \\
\text { Sig0.002 } \\
* *\end{array}$ & $\begin{array}{l}0.144 \mathrm{Sig} \\
0.50\end{array}$ & $\begin{array}{l}0.033 \mathrm{Sig} \\
0.354\end{array}$ & $\begin{array}{l}0.360 \\
\text { Sig0.000 } \\
* * *\end{array}$ & $\begin{array}{l}1.000 \text { Sig } \\
0.000\end{array}$ \\
\hline
\end{tabular}

Pearson Correlation Coefficients between Variables experience and rating average had significant impact are shown in Table 6 represents the carrier on the job performance of the employees working in advancement, educational, performance, age, gender, the selected IT companies in Hyderabad.

Table 7: Pearson Correlation Coefficients between Average Performance rating

\begin{tabular}{|l|c|c|}
\hline \multicolumn{1}{|c|}{ Variable } & $\begin{array}{c}\text { Pearson Correlation Coefficient } \\
\text { Performance Rating }\end{array}$ & $\begin{array}{c}\text { Sig. } \\
(1-\text { tailed })\end{array}$ \\
\hline Performance & 0.324 & $0.007 * *$ \\
\hline Sociability & 0.289 & $0.025^{*}$ \\
\hline Emotionality & 0.268 & $0.008^{* *}$ \\
\hline Self-Control & 0.254 & $0.030^{*}$ \\
\hline Well Being & 2.44 & 0.058 \\
\hline
\end{tabular}

Pearson Correlation Coefficients between Average significant tailed and the factors presented proved the Performance rating parameters presented in Table 7 hypothesis of all the above factors had a positive represents performance 0.324, Sociability 0.289, impact on the improving the employees job Emotionality 0.268 , self control0.254, and well being performance and organizational performance of the 2.44. Based on the Pearson Correlation Coefficient selected IT companies surveyed in Hyderabad.

Table 8: Descriptive Statistics of Normal Distribution for Relevant Variables

\begin{tabular}{|l|c|c|c|c|c|c|c|c|c|}
\hline \multicolumn{1}{|c|}{ Factors } & Sample & Tolerance & VIF & Mean & $\begin{array}{c}\text { Std. } \\
\text { Deviation }\end{array}$ & \multicolumn{2}{c|}{ Skewness } & \multicolumn{2}{c|}{ Kurtosis } \\
\hline & Statistic & Statistic & Statistic & Statistic & Statistic & Statistic & $\begin{array}{c}\text { Std. } \\
\text { Error }\end{array}$ & Statistic & $\begin{array}{c}\text { Std. } \\
\text { Error }\end{array}$ \\
\hline Educational & 244 & 0.999 & 1.004 & 7.124 & 1.52065 & 0.606 & 0.322 & -0.199 & 0.419 \\
\hline $\begin{array}{l}\text { Career } \\
\text { Advancement }\end{array}$ & 256 & 0.987 & 1.002 & 7.344 & 2.6169 & 0.786 & 0.345 & 2.245 & 0.419 \\
\hline Performance & 242 & 0.999 & 1.002 & 8.456 & 2.6442 & 0.642 & 0.365 & 2.786 & 0.419 \\
\hline
\end{tabular}


Descriptive Statistics of Normal Distribution for Relevant Variables such as educational, career advancement and performance factors, mean value, standard deviation, skewness and courtesies tests are proved the all these factors relevance to the emotional intelligence and employees job performance of the IT Companies.

\section{Findings and Suggestions:}

At present business, the emotional intelligence and job satisfaction are the two concepts in high focus for employee delight and corporates productivity and profitability. Also, these two aspects serve as a competitive edge in the personallife and organizational growth. The main objective of this study had examined the relationship between the emotional intelligence and job satisfaction factors. The findings were made after the data analysis, with the help of standard statistical tools such as Karl Pearson coefficient of correlation, Analysis of variance (ANOVA), Student's t- test and other statistics and inferences have been drawn.

The hypotheses has been formulated for testing based on appropriate statistical tests proved that there had a significant relation existing between the job satisfaction and emotional intelligence of the employees in terms of designation and experience highly impacting on improving the IT companies performance and work culture.

It is observed that the different motivation factors are significantly correlated with the factors like degree of autonomy and decision making capacity associated with the job of a person in an organization. It would also include the factors that would make the jobs more intrinsically rewarding which include the interesting content, conducive team environment, importance of the work, relationships, good leadership and various other factors which change from time to time.

Emotional Intelligence and its impact on Employees Job satisfaction in IT companies: A case study factors such as Adoptability 74\%, Assertiveness 68\%, Emotional appraisal 79\%, Emotion Control 87\%, Emotion expression $95 \%$ etc had highly accepted by the majority of the respondents.

Emotional intelligence and job performance standard factors loadings of Job holders goals and performance acceptable level $0.824 \%$, Job holders have achieved most of their goals by performing key responsibilities $0.925 \%$, have significantly exceeded a fully acceptable level $0.852 \%$. All these factors had highly influencing the improving the employees job performance in terms of goal achievement superiors subordinate relations and performance related factors.

Descriptive statistics of Emotional Intelligence and Job performance factors had highly influenced by emotional intelligence with age, mean values 3.77 , experience 8.57 , performance traits 4.56 , Sociability 4.97, emotionality 5.64, self-control 4.87, etc. All these mean values and standard deviation values had positively correlated by establishing a positive kind of inter relationship between emotional intelligence by proving the hypothesis at positive level.

Reliability Analysis of Emotional Intelligence and Job performance factors considered by Cronbach's Alpha test in respect of work culture 0.988, Performance at work 0.977, Career Advancement 0.866, Educational Attainment 0.877 . The reliability test had given a positive kind of relationship and positive results in respect of emotional intelligence and the above key factors.

Pearson Correlation Coefficients variables had tested with the carrier advancement, educational, performance, age, gender, experience and rating average had significant impact on the job performance of the employees working in the selected IT companies in Hyderabad.

Descriptive Statistics of Normal Distribution for Relevant Variables such as educational, career advancement and performance factors, mean value, standard deviation, skewness and courtesies tests had also proved that all these factors and its relevance on the emotional intelligence and employees job performance of the IT Companies.

\section{References:}

1. Petrides, K.V., \&Furnham, A. (2000). On the dimensional structure of emotional intelligence. Personality and Individual Differences

2. Zainal, S.R.M., Nasurdin, A.M., \&Hoo, Q.C. (2012). The Role of Emotional Intelligence towards the career success of Hotel. International Conference on Economics, Business and Management IPEDR

3. Zeidner, M., Matthews, G., \& Roberts, R.D. (2004). Emotional Intelligence in the Workplace: A Critical Review. Applied Psychology: An International Review,

4. Kumari, G., \& Pandey, K.M. (2011, June). Job Satisfaction in Public Sector and Private Sector: A Comparison. International Journal of Innovation, Management and Technology 